\title{
Metal ion-mediated potential-resolved ratiometric electrochemiluminescence bioassay for efficient determination of miR-133a in early diagnosis of acute myocardial infarction
}

Jue Wang ${ }^{+}$, M ohammad A. H aghighatbin ${ }^{+}$, Wen Shen ${ }^{+}, \mathrm{L}$ an $\mathrm{M} \mathrm{i}^{+}, \mathrm{H}$ ua C ui ${ }^{+},{ }^{*}$

+CAS Key Laboratory of Soft Matter Chemistry, iChEM (Collaborative Innovation Center of Chemistry for Energy Materials), Department of Chemistry, U niversity of Science and T echnology of C hina, H efei, Anhui 230026, P. R. China

*E-mail: hcui@ustc.edu.cn; Fax: +86-551-63600730 


\section{Table of Contents}

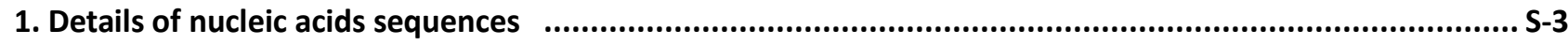

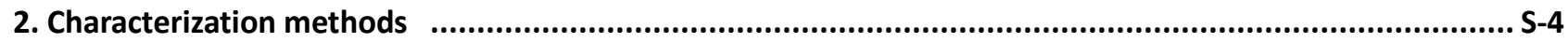

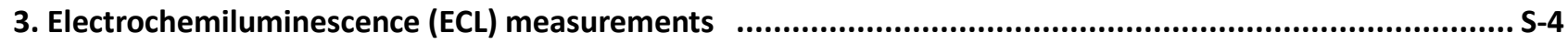

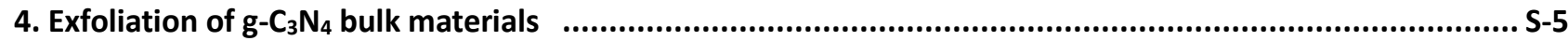

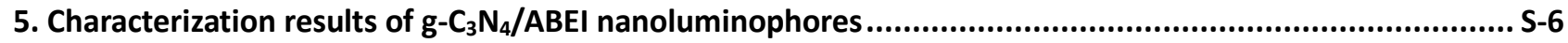

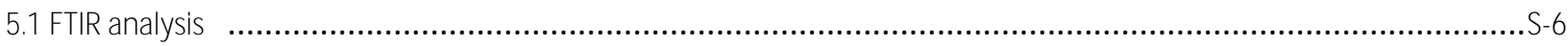

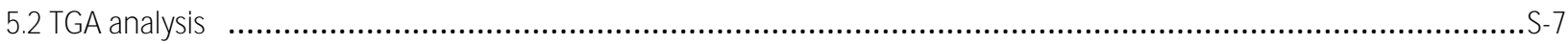

6. Measurement of relative $\mathrm{ECL}$ efficiency of $\mathrm{g}-\mathrm{C}_{3} \mathrm{~N}_{4} / \mathrm{ABEI}$ nanoluminophores.......................................... S-8

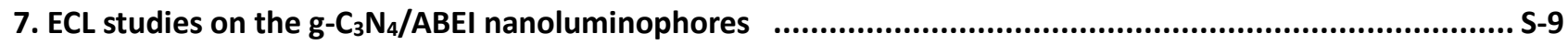

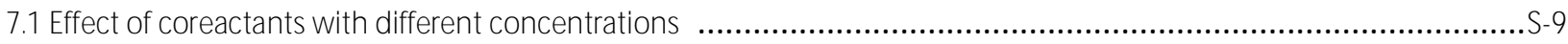

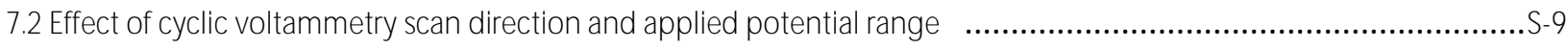

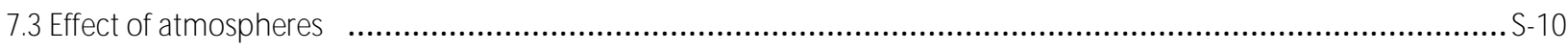

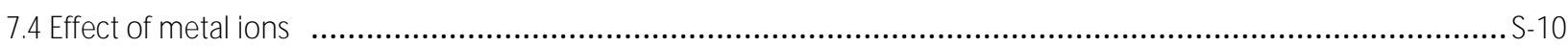

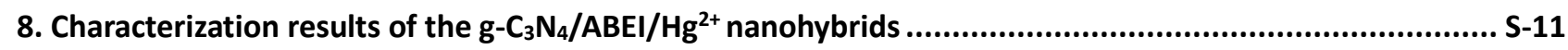

9. Optimization of experimental conditions for miRNA-133a bioassay .............................................. S-12

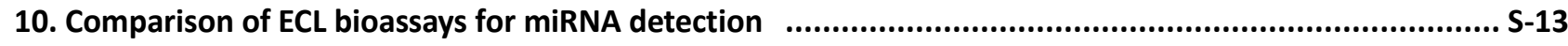

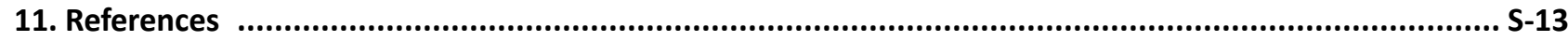


1. Details of nucleic acids sequences

T able S1. Sequences of nucleic acids used in experiments

\begin{tabular}{|l|l|}
\hline \multicolumn{1}{|c|}{ Name } & \multicolumn{1}{c|}{ Sequence (5'-3') } \\
\hline P133 & $\begin{array}{l}\text { Phosphate- } \\
\text { TTTTACCAGCTAAAAAAAAAACGCATCGCGCGCAACGCAAAAAAAAAAATTTGGTTCCA }\end{array}$ \\
\hline miRNA-133a & AGCUGGUAAAUGGAACCAAAU \\
\hline M1 & AGCUGGUAAAUUGGAACCAAAU \\
\hline M2 & AGCUGGUAAAAGGAACCAAAU \\
\hline M3 & AGCUGGUAAAU $\underline{\mathbf{C} G A A C C A A A U}$ \\
\hline M4 & AGCUGGUAAAUG $\underline{\mathbf{C A A C C A A A U}}$ \\
\hline M5 & AGCUGGUAAAUGGAUCCAAAU \\
\hline M6 & AGCUGGUAAAUGGACGAAUU \\
\hline
\end{tabular}




\section{Characterization methods}

The g- $\mathrm{C}_{3} \mathrm{~N}_{4} / \mathrm{ABEI}$ nanoluminophores were characterized by UV-visible spectrophotometer (UV-vis, Agilent 8453, Agilent Technologies, USA), Fluorescence Spectrophotometer (FL, F-7000, Hitachi, Japan) with a 150 W Xenon lamp as the light source, Fourier Transform Infrared Spectroscopy (FTIR, EQUINX55, Bruker, Germany), Transmission Electron Microscopy (TEM, JEM-2011, JEOL, Japan), Atomic Force Microscopy (AFM, Dimension Icon, Bruker, USA), Atomic Fluorescence Spectrometry (AFS, AFS-230Q, China), Thermal Gravimetric Analyzer (TGA, TGA Q5000IR, TA, USA) and X-ray Photoelectron Spectroscopy (XPS, ESCALAB 250, Thermo-VG Scientific, UK) with Al Ka radiation as the Xray source. The prepared nanoluminophore was purified by multiple centrifugation and re-dispersion steps in order to obtain valid information from the surface analysis of the $\mathrm{g}-\mathrm{C}_{3} \mathrm{~N}_{4} / \mathrm{ABEI}$ by various characterization methods. The precipitates were dried under vacuum at $60^{\circ} \mathrm{C}$ for TGA and FTIR measurements. The precipitates were further redispersed in $\mathrm{H}_{2} \mathrm{O}$ for UV-vis and $\mathrm{FL}$ analysis. The re-dispersed solution was dripped on designated substrates and dried naturally at room temperature for TEM, AFM and XPS characterizations.

\section{Electrochemiluminescence (ECL) measurements}

ECL measurements were carried out in a custom-made ECL system (Scheme S1) consisting of an H-type electrochemical cell, an electrochemical workstation (CHI 760D, Chenhua, China) and an ultra-weak chemiluminescence/bioluminescent detector (RFL-1A, Remex, China) equipped with a CR-105 photomultiplier tube (PMT, Bingsong, China). A conventional three-electrode system: $\mathrm{Ag} / \mathrm{AgCl}$ (saturated $\mathrm{KCl}$ ) as the reference electrode, a platinum wire as the counter electrode and a fluorine-doped tin oxide (FTO) electrode modified with the prepared nanohybrids as the working electrode was used throughout the ECL experiments.

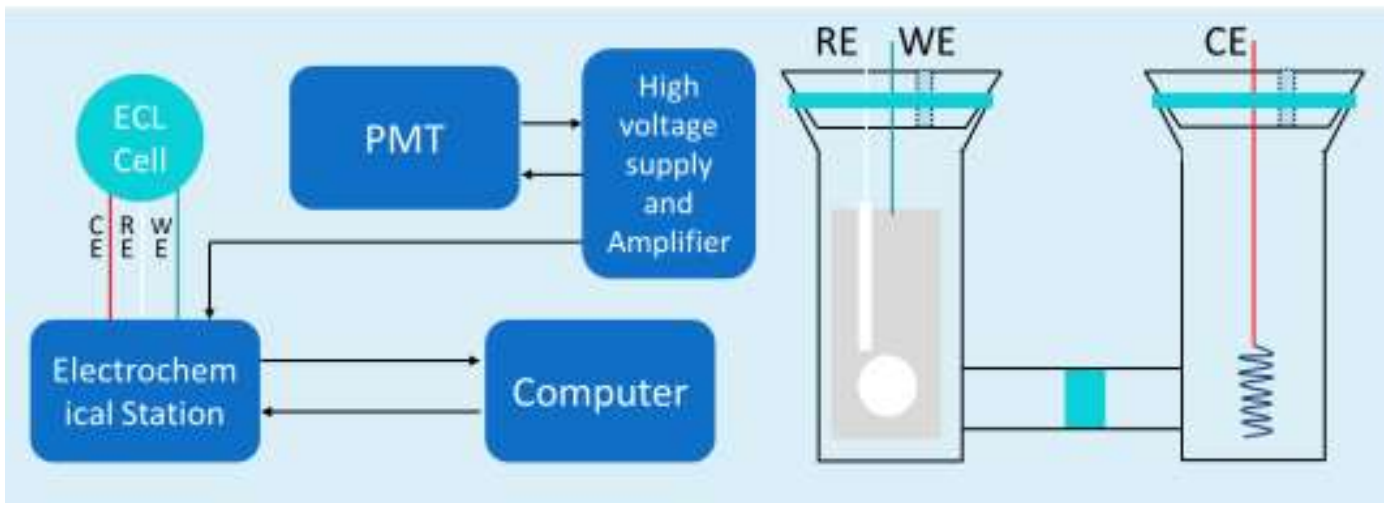

Scheme S1. C ustom-made ECL instrumental setup (left) and ECL cell in a conventional three-electrode setup (right). 


\section{Exfoliation of g- $\mathrm{C}_{3} \mathrm{~N}_{4}$ bulk materials}

In order to get higher yield of $\mathrm{g}-\mathrm{C}_{3} \mathrm{~N}_{4}$ nanosheets, $\mathrm{H}_{2} \mathrm{O} / \mathrm{EtOH}$ mixed solutions at different volume ratios were used as the sonication solvent in our synthetic procedure. As shown in Figure $S 1$, the absorbance of $g-C_{3} N_{4}$ nanosheets reached its maximum when the volume ratio of EtOH was at $55 \%\left(\mathrm{~V}_{\mathrm{EtOH}}=55 \%\right)$, indicating that the mixture with a volume ratio of $\mathrm{V}_{\mathrm{EtOH}}=55 \%$ was the optimum ratio for a higher exfoliation yield.
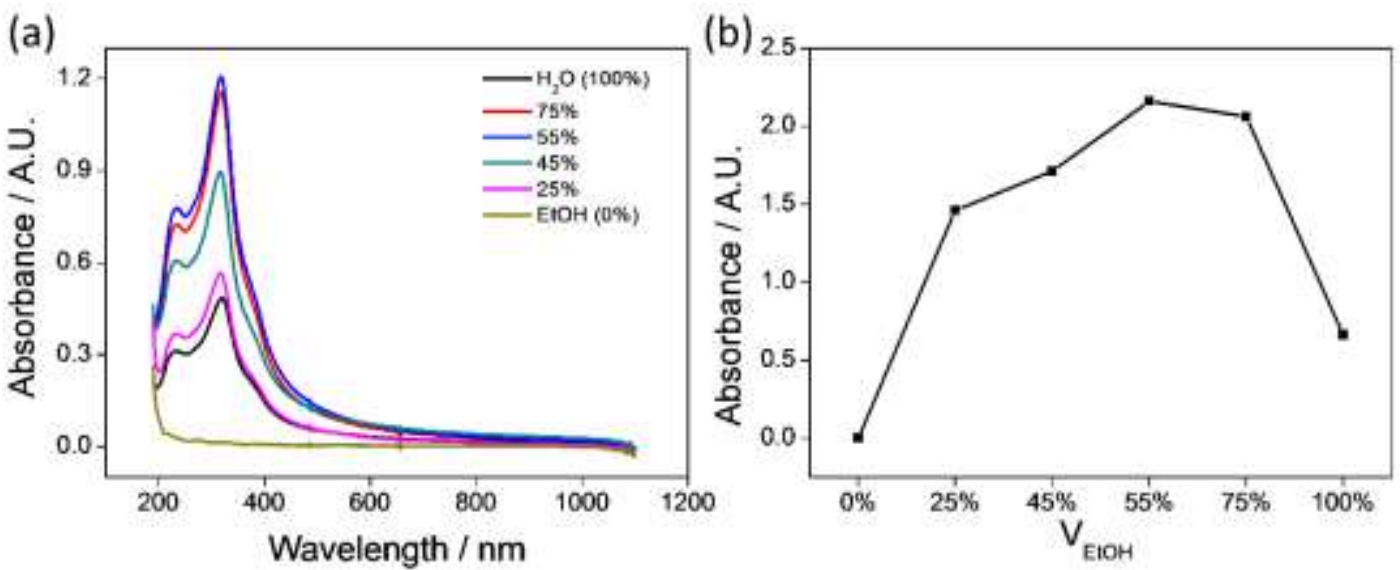

Figure S1. Exfoliation effect of $g-\mathrm{C}_{3} \mathrm{~N}_{4}$ bulk materials in $\mathrm{H}_{2} \mathrm{O} / \mathrm{EtOH}$ mixture with different volume ratio. (a) UV-vis spectra of $g-\mathrm{C}_{3} \mathrm{~N}_{4}$ nanosheets after exfoliation and (b) the relationship between UV-vis absorbance at $320 \mathrm{~nm}$ and EtO $\mathrm{H}$ volume ratio. 


\section{Characterization results of $\mathrm{g}-\mathrm{C}_{3} \mathrm{~N}_{4} / \mathrm{ABEI}$ nanoluminophores}

\subsection{FTIR analysis}

The sharp peak at $807 \mathrm{~cm}^{-1}$ was attributed to the breathing vibration of s-triazine ring. The signals presented at $1200-1600 \mathrm{~cm}^{-1}$ were the characteristic of aromatic carbon nitride heterocycles. The broad absorption band at $3000-3500 \mathrm{~cm}^{-1}$ could be assigned to $\mathrm{N}-\mathrm{H}$ and $\mathrm{O}-\mathrm{H}$ stretching vibrations. Comparison between the FTIR spectrum of $\mathrm{g}-\mathrm{C}_{3} \mathrm{~N}_{4} / \mathrm{ABEI}$ and of $\mathrm{g}-\mathrm{C}_{3} \mathrm{~N}_{4}$ shows that a broader band for $\mathrm{g}-\mathrm{C}_{3} \mathrm{~N}_{4} / \mathrm{ABEI}$ at $3000-3500 \mathrm{~cm}^{-1}$ while the other peaks remained nearly the same, indicating that the chemical structure of $\mathrm{g}-\mathrm{C}_{3} \mathrm{~N}_{4}$ nanosheets was retained with a possibility of forming stronger intermolecular hydrogen bonding after being functionalized with ABEI.

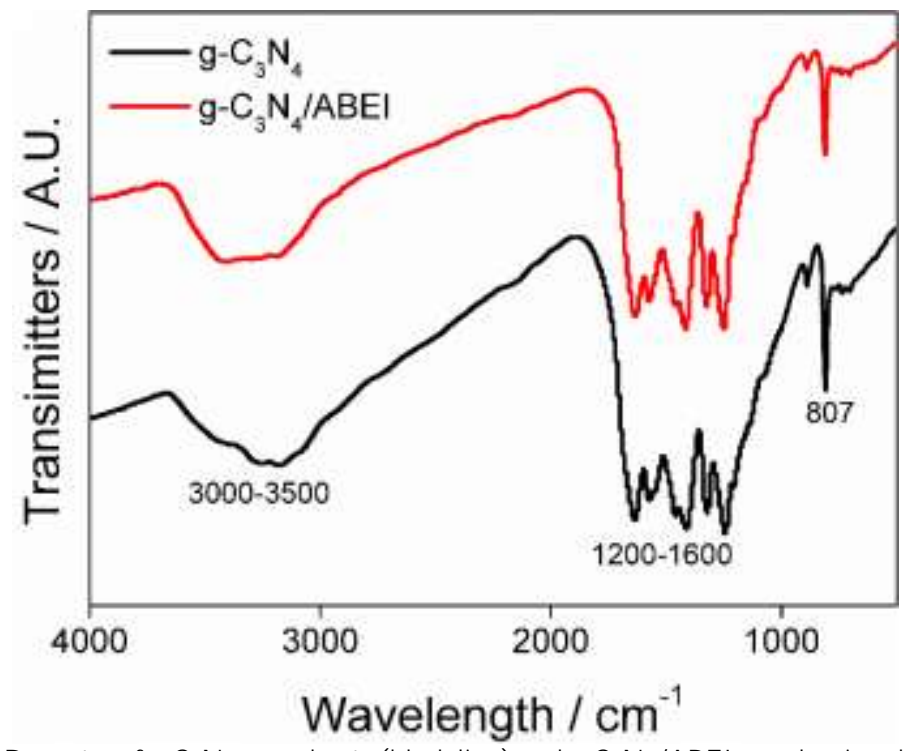

Figure S2. FT -IR spectra of $g-\mathrm{C}_{3} \mathrm{~N}_{4}$ nanosheets (black line) and $\mathrm{g}-\mathrm{C}_{3} \mathrm{~N}_{4} / \mathrm{ABEI}$ nanoluminophores (red line). 


\subsection{TGA analysis}

TGA curves of ABEI, $g-\mathrm{C}_{3} \mathrm{~N}_{4}$ and $\mathrm{g}-\mathrm{C}_{3} \mathrm{~N}_{4} / \mathrm{ABEI}$ are shown in Figure $\mathrm{S} 3$. ABEI had three weight-loss stages: from 250 to $340^{\circ} \mathrm{C}$, representing $\mathrm{HN}-\mathrm{NH}$ decomposition; from 340 to $490^{\circ} \mathrm{C}$, the main pyrolysis process, being assigned to fatty-amine chain; after $490^{\circ} \mathrm{C}$, the weight loss was due to benzene skeleton decomposition. The pure g- $\mathrm{C}_{3} \mathrm{~N}_{4}$ nearly lost its whole weight from 550 to 765 ${ }^{\circ} \mathrm{C}$. The g- $\mathrm{C}_{3} \mathrm{~N}_{4} / \mathrm{ABEI}$ showed a similar TGA profile with $\mathrm{g}-\mathrm{C}_{3} \mathrm{~N}_{4}$, but its initial decomposition temperature at $413^{\circ} \mathrm{C}$ was lower than that of pure $\mathrm{g}-\mathrm{C}_{3} \mathrm{~N}_{4}$ and close to the second-stage initial pyrolysis temperature of $\mathrm{ABEI}$, which demonstrated that $\mathrm{ABEI}$ existed on the surface of $g-C_{3} \mathrm{~N}_{4}$ as expected.

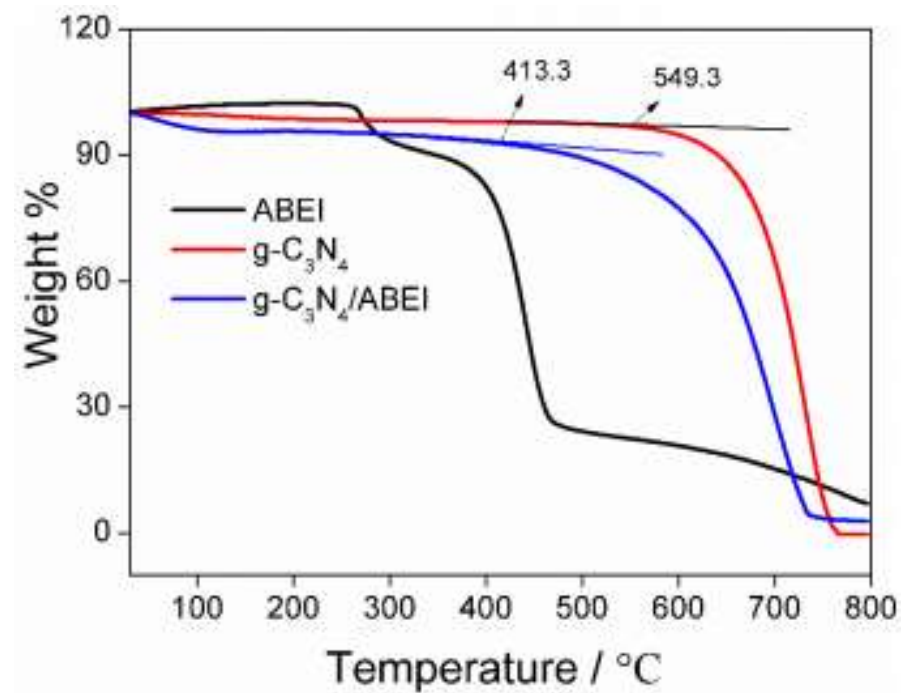

Figure S3. Thermogravimetric analysis of pure $A B E I$ (black line), $g-C_{3} N_{4}$ (red line) and $g-C_{3} N_{4} / A B E I$ nanoluminophores (blue line). 


\section{Measurement of relative ECL quantum efficiency of g- $\mathrm{C}_{3} \mathrm{~N}_{4} / \mathrm{ABEI}$ nanoluminophores}

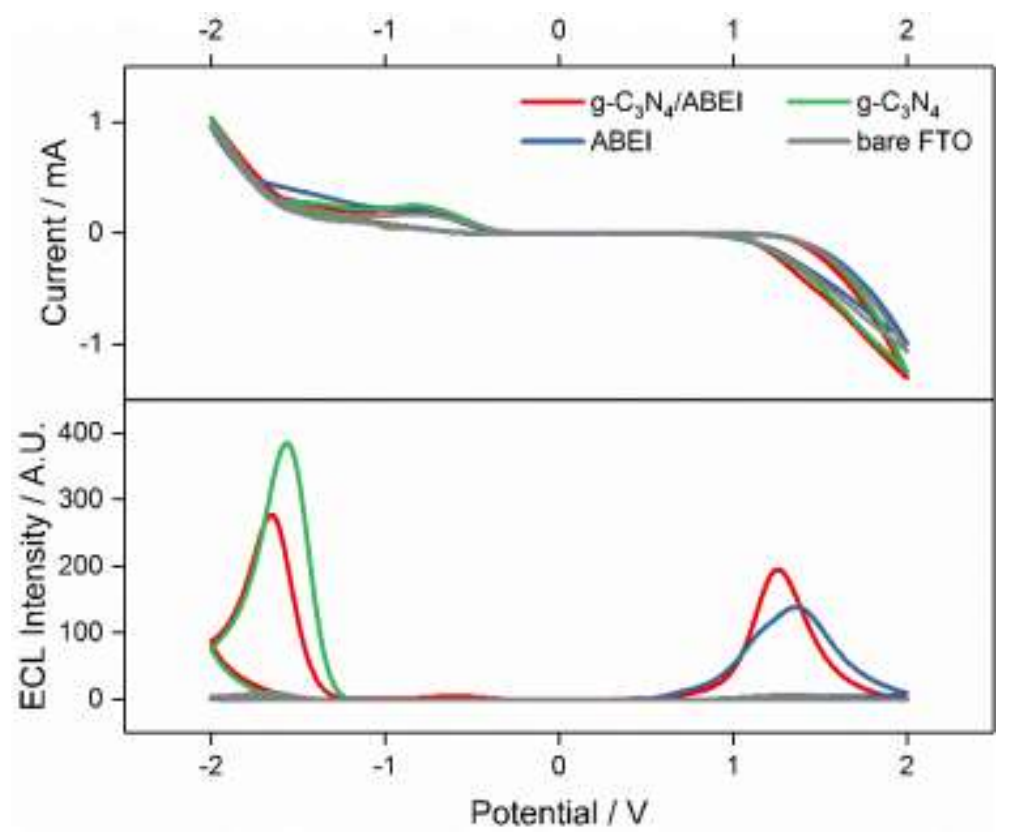

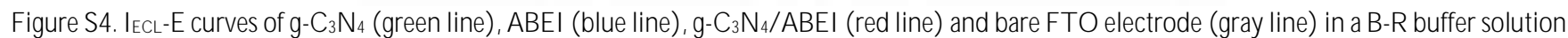
$(\mathrm{pH}=11)$ containing $1 \mathrm{mM} \mathrm{K} \mathrm{S}_{2} \mathrm{O}_{8}-\mathrm{H}_{2} \mathrm{O}_{2}$. Scan rate: $0.1 \mathrm{~V} / \mathrm{s}$.

The ECL quantum efficiency ( $\Phi_{\mathrm{ECL}}$ ) is defined as the number of photons emitted per redox event. However, the direct measurement of $\Phi_{\mathrm{ECL}}$ for coreactant systems is impossible due to the complexity of coreactant systems, the irreversible nature of coreactant electrochemistry and the high concentrations of coreactants in solution compared to luminophore. Usually, a relative ECL quantum efficiency is reported in the coreactant system using suitable standard. Accordingly, we carried out the measurement of relative ECL quantum efficiency of the coreactant systems. Here, $\mathrm{ABEI} / \mathrm{K}_{2} \mathrm{~S}_{2} \mathrm{O}_{8}-\mathrm{H}_{2} \mathrm{O}_{2}$ for ECL-1 and g- $\mathrm{C}_{3} \mathrm{~N}_{4} / \mathrm{K}_{2} \mathrm{~S}_{2} \mathrm{O}_{8}-\mathrm{H}_{2} \mathrm{O}_{2}$ for ECL-2 are designated as the reference systems in the identical conditions. $\left(\Phi_{\mathrm{r}}=\Phi_{\mathrm{ECL}}^{\circ}\left(\mathrm{IQ}^{\circ} / \mathrm{I}^{\circ} \mathrm{Q}\right)\right.$, where $\mathrm{I}$ is the integrated $\mathrm{ECL}$ intensities, $Q$ is the charges passed (in coulombs), $\Phi^{\circ}{ }_{\mathrm{ECL}}=1$ ). The result is shown in the following table.

\begin{tabular}{|l|c|}
\hline ECL-1 (vs. ABEI $<1 \mu \mathrm{M}>/ \mathrm{K}_{2} \mathrm{~S}_{2} \mathrm{O}_{8}-\mathrm{H}_{2} \mathrm{O}_{2}$ ) & $73 \%$ \\
\hline ECL-2 (vs. g- $\mathrm{C}_{3} \mathrm{~N}_{4}<0.2 \mathrm{mg} / \mathrm{mL}>/ \mathrm{K}_{2} \mathrm{~S}_{2} \mathrm{O}_{8}-\mathrm{H}_{2} \mathrm{O}_{2}$ ) & $69 \%$ \\
\hline
\end{tabular}

${ }^{a}$ based on averaged results from 3 independent measurements 


\section{ECL studies on the $\mathrm{g}-\mathrm{C}_{3} \mathrm{~N}_{4} / \mathrm{ABEI}$ nanoluminophores}

\subsection{Effect of coreactants with different concentration}

(a)

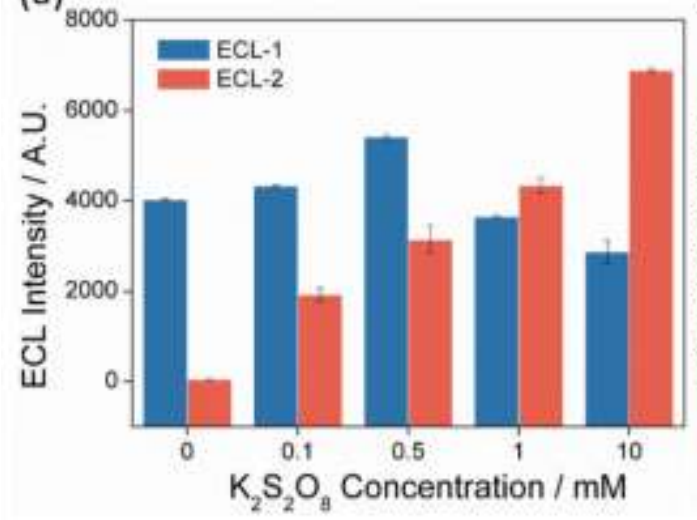

(b)

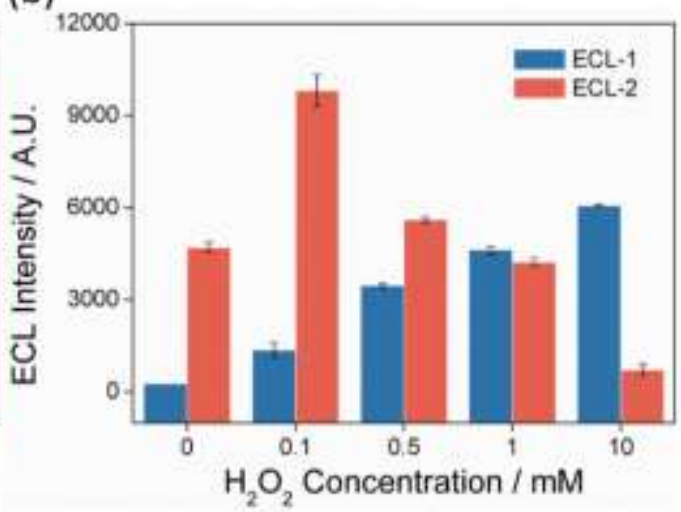

Figure S5. Effect of coreactant concentration on the $\mathrm{ECL}$ intensities concentration. $\mathrm{ECL}$ intensity variations at different concentrations of $(\mathrm{a}) \mathrm{K}_{2} \mathrm{~S}_{2} \mathrm{O}_{8}$ when $\mathrm{c}\left(\mathrm{H}_{2} \mathrm{O}_{2}\right)=1.0 \mathrm{mM}$ and $(\mathrm{b}) \mathrm{H}_{2} \mathrm{O}_{2}$ when $\mathrm{c}\left(\mathrm{K}_{2} \mathrm{~S}_{2} \mathrm{O}_{8}\right)=1.0 \mathrm{mM}$.

\subsection{Effect of cyclic voltammetry scan direction and applied potential range}

(a)

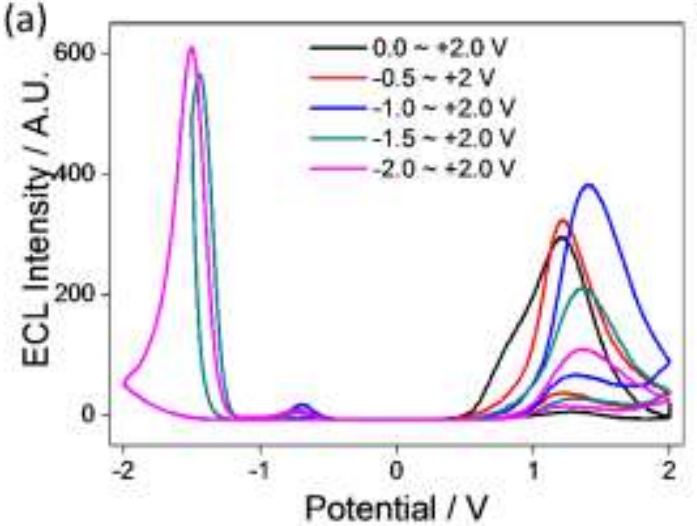

(b)

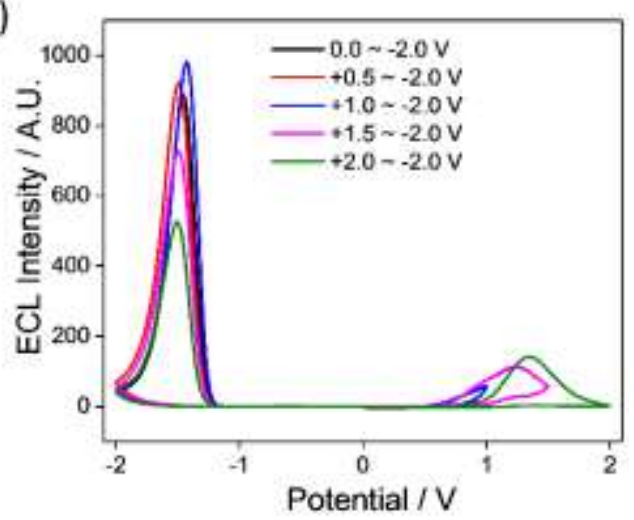

Figure S6. Effect of potential scan direction and range on the ECL intensities. IECL-E curves of $\mathrm{g}-\mathrm{C}_{3} \mathrm{~N}_{4} / \mathrm{ABEl}$ with an initial scan towards (a) negative potentials and different negative potential limits in the reverse scans and (b) positive potentials with different positive potential limits in the reverse scan. 


\subsection{Effect of atmospheres}
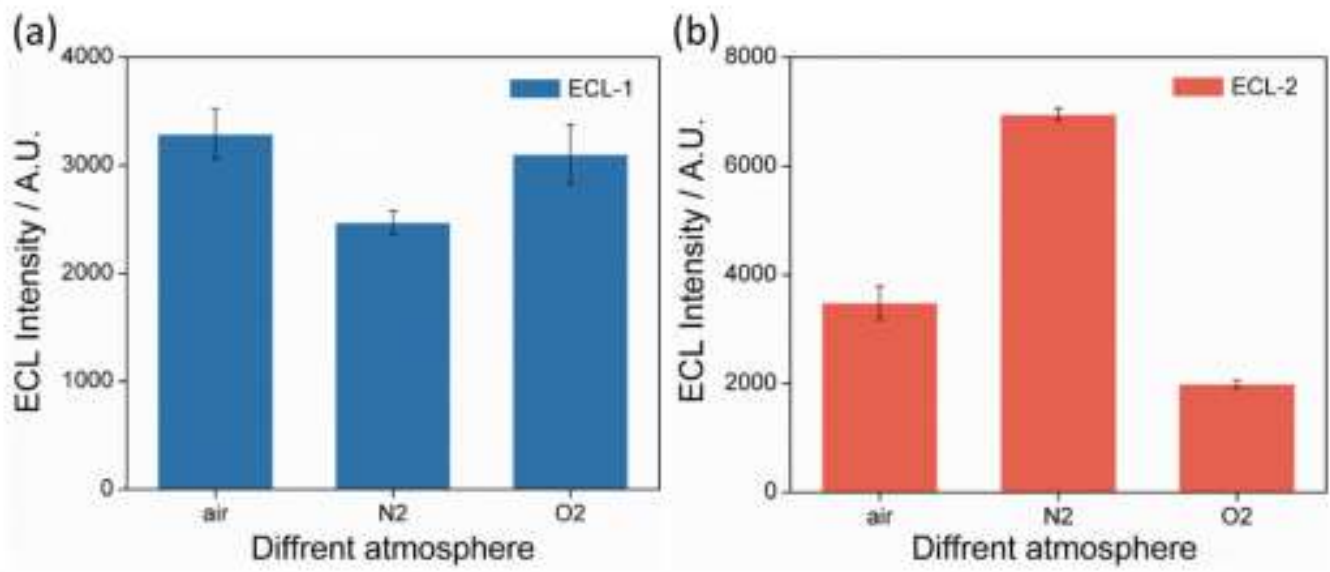

Figure S7. Effect of different atmospheres on the (a) ECL-1 and (b) ECL-2 intensities of the $\mathrm{g}_{3} \mathrm{C}_{3} \mathrm{~N}_{4} / \mathrm{ABEI}$.

\subsection{Effect of metal ions}

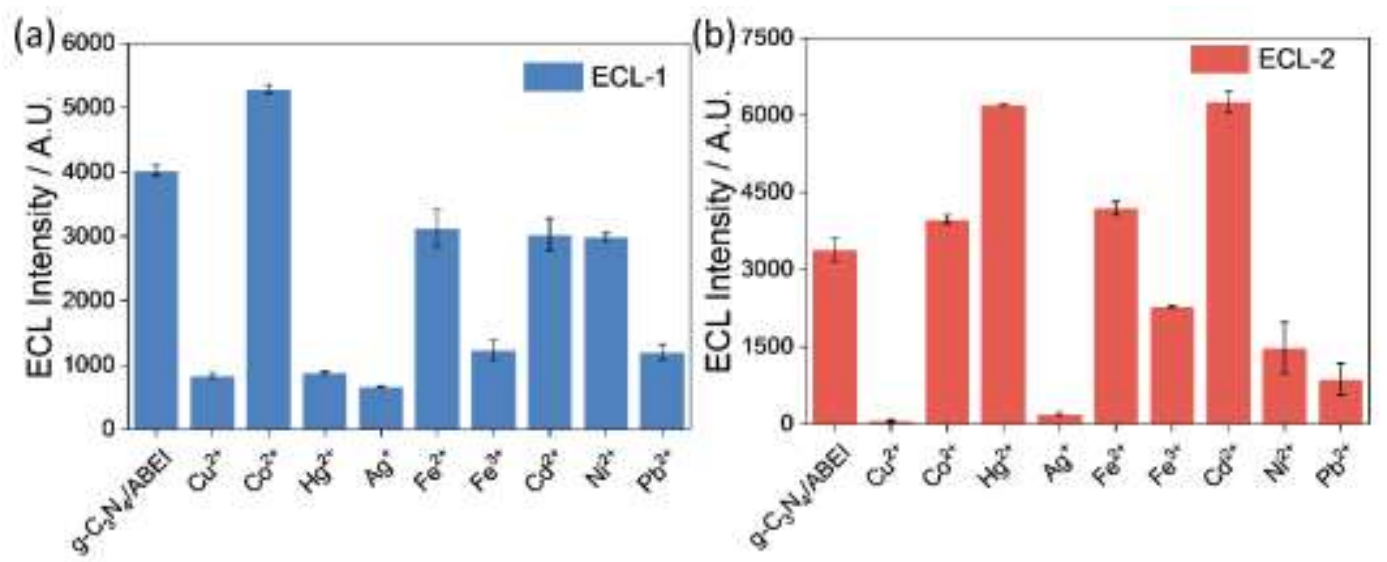

Figure S8. Effect of different metal-ion substitutions on the (a) ECL-1 and (b) ECL-2 intensities of the $g-C_{3} \mathrm{~N}_{4} / A B E l$. 


\section{Characterization results of the $\mathrm{g}-\mathrm{C}_{3} \mathrm{~N}_{4} / \mathrm{ABEI} / \mathrm{Hg}^{2+}$ nanohybrids}

g- $\mathrm{C}_{3} \mathrm{~N}_{4}$, with rich nitrogen lone-pair electrons in the covalent polymeric framework, is generally considered as an ideal heterogeneous scaffold for metal doping (e.g. $\mathrm{Fe}^{3+}, \mathrm{Co}^{2+}$ ) mainly due to strong interactions between the cations and the negatively charged nitrogen atoms. Thus, we speculated that $\mathrm{Hg}^{2+}$ could be incorporated to the $\mathrm{g}-\mathrm{C}_{3} \mathrm{~N}_{4} / \mathrm{ABEI}$ by the virtue of electrostatic interaction and coordination interactions, forming $\mathrm{g}-\mathrm{C}_{3} \mathrm{~N}_{4} / \mathrm{ABEI} / \mathrm{Hg}^{2+}$ nanohybrids. Specifically, $5 \mathrm{mM} \mathrm{HgCl}$ solution was interacted with the obtained $\mathrm{g}-\mathrm{C}_{3} \mathrm{~N}_{4} / \mathrm{ABEI}$ suspension with a volume ratio of $1: 4$ for 30 minutes. After centrifugation and redispersion, $\mathrm{g}-\mathrm{C}_{3} \mathrm{~N}_{4} / \mathrm{ABEl} / \mathrm{Hg}^{2+}$ nanohybrids were obtained. Zeta-potential measurements were carried out and the value of $\mathrm{g}$ $\mathrm{C}_{3} \mathrm{~N}_{4} / \mathrm{ABEI}$ and $\mathrm{g}-\mathrm{C}_{3} \mathrm{~N}_{4} / \mathrm{ABEI} / \mathrm{Hg}^{2+}$ were measured to be -30.8 and $-5.5 \mathrm{mV}$ in aqueous solutions, respectively. The positive shift of $25.3 \mathrm{mV}$ indicated that the positively charged $\mathrm{Hg}^{2+}$ could be embedded on the surface of negatively charged $g-\mathrm{C}_{3} \mathrm{~N}_{4} / \mathrm{ABEI}$ via electrostatic interactions. The further XPS studies (Figure S9) also demonstrated that $\mathrm{Hg}^{2+}$ could also be attached to g- $\mathrm{C}_{3} \mathrm{~N}_{4} / \mathrm{ABEI}$ through coordination interactions between $\mathrm{Hg}^{2+}$ and $\mathrm{N}$ or $\mathrm{O}$ atoms from $\mathrm{g}-\mathrm{C}_{3} \mathrm{~N}_{4} / \mathrm{ABEI}$ to form $\mathrm{Hg}-\mathrm{N}$ or $\mathrm{Hg}-\mathrm{O}$ moieties. The

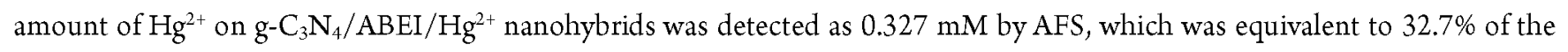
total added $\mathrm{Hg}^{2+}$ amount.

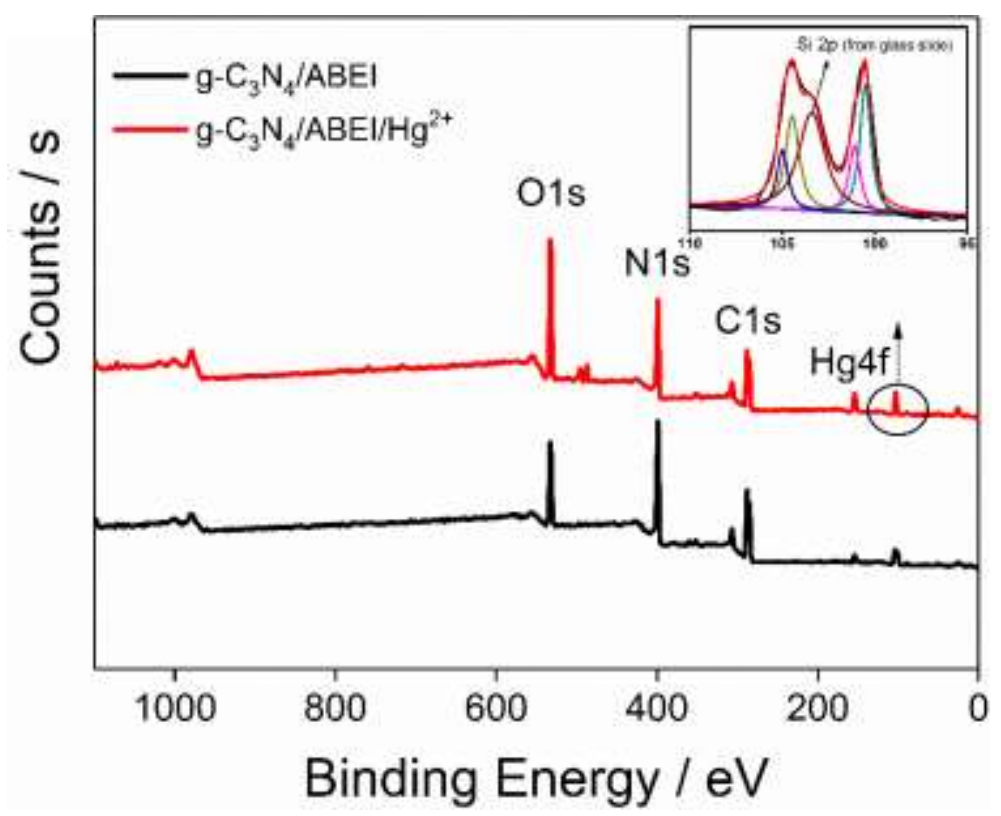

Figure S9. XPS survey of the $\mathrm{g}-\mathrm{C}_{3} \mathrm{~N}_{4} / \mathrm{ABEl}$ and $\mathrm{g}-\mathrm{C}_{3} \mathrm{~N}_{4} / \mathrm{ABEl} / \mathrm{H} \mathrm{g}^{2+}$ nanohybrids. Inset: high resolution scan of $\mathrm{H}$ g4f. 
9. Optimization of experimental conditions for miRNA-133a bioassay

(a)

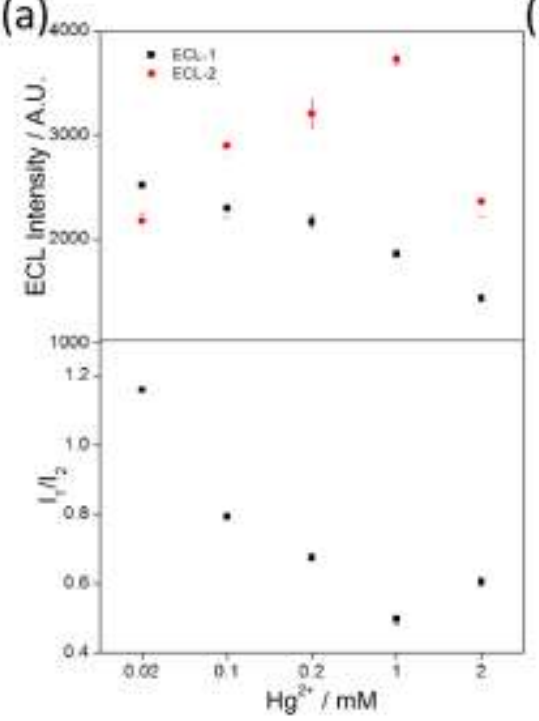

(b)

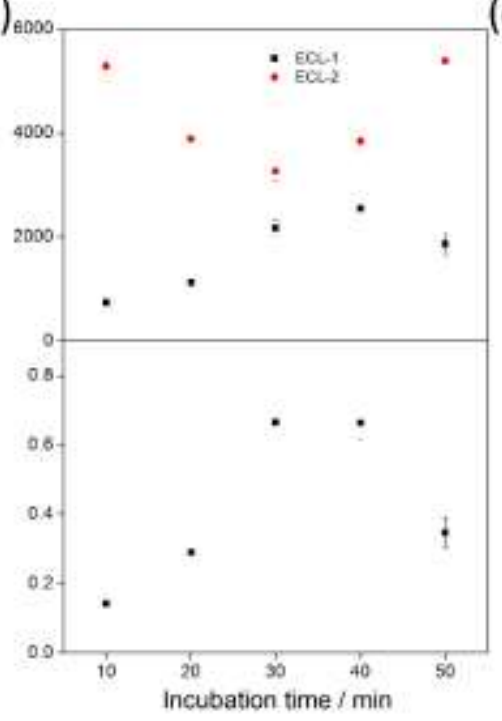

(c)

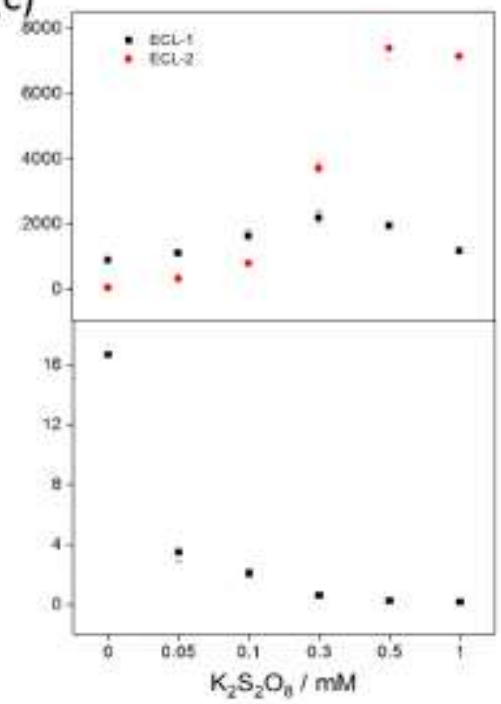

Figure S10. Effect of (a) $\mathrm{H} \mathrm{g}^{2+}$ concentration, (b) incubation time and (c) $\mathrm{K}_{2} \mathrm{~S}_{2} \mathrm{O}_{8}$ concentration on ECL intensities and the corresponding $\mathrm{I}_{1} / \mathrm{I}_{2}$ of the proposed biosensor. $\mathrm{H}_{2} \mathrm{O}_{2}$ concentration: $1.0 \mathrm{mM}$, miRN A-133a concentration: $0.1 \mathrm{pM}$. 
10. Comparison of ECL bioassays for miRNA detection

TableS2. A comparison of various ECL bioassays for miRNA determination

\begin{tabular}{|c|c|c|c|c|}
\hline Sensing platform & Target & Linear range & Detection limit & Ref. \\
\hline $\mathrm{mSiO}_{2} @ \mathrm{CdTe} @ \mathrm{SiO}_{2}$ & miRNA-182 & $0.1 \mathrm{pM}$ to $100 \mathrm{pM}$ & $33 \mathrm{fM}$ & {$[1]$} \\
\hline $\begin{array}{c}\text { g-C } \mathrm{C}_{3} \mathrm{~N}_{4} @ \text { @ AuNPs and Ru- } \\
\text { MOF nanosheets }\end{array}$ & $\begin{array}{l}\text { miRNA-141 and } \\
\text { miRNA-21 }\end{array}$ & $1 \mathrm{fM}$ to $10 \mathrm{pM}$ & $0.3 \mathrm{fM}$ & {$[2]$} \\
\hline TiO ${ }_{2} @$ PEI-Ru@SA & microRNA-21 & $0.5 \mathrm{fM}$ to $10 \mathrm{pM}$ & $0.24 \mathrm{fM}$ & {$[3]$} \\
\hline $\begin{array}{c}\text { Au NP-luminol-LDH and } \\
\text { Au NCs }\end{array}$ & miRNA-107 & $10 \mathrm{aM}$ to $100 \mathrm{pM}$ & $9.4 \mathrm{aM}$ & {$[4]$} \\
\hline $\begin{array}{c}\text { AuNPs@G4 SNAzyme and } \\
\text { Luminol- } \mathrm{H}_{2} \mathrm{O}_{2}\end{array}$ & miRNA-133a & $1 \mathrm{fM}$ to $1 \mathrm{nM}$ & $0.4 \mathrm{fM}$ & {$[5]$} \\
\hline $\mathrm{g}-\mathrm{C}_{3} \mathrm{~N}_{4} / \mathrm{ABEI} / \mathrm{Hg}^{2+}$ & miRNA-133a & $0.1 \mathrm{fM}$ to $1.0 \mathrm{pM}$ & $48.0 \mathrm{aM}$ & This work \\
\hline
\end{tabular}

\section{REFERENCES}

(1) Zhu, H .-Y.; Ding, S.-N . Biosens. Bioelectron. 2019, 134, 109-116.

(2) Shao, H .; Lin, H .; Lu, J.; H u, Y.; W ang, S.; H uang, Y.; Guo, Z. Biosens. Bioelectron. 2018, 118, 247-252.

(3) Chen, A.; Zhuo, Y.; Chai, Y.; Yuan, R. Chem. Commun. 2019, 55, 13932-13935..

(4) Huo, X.-L.; Zhang, N ; Yang, H.; Xu, J.-J.; Chen, H .-Y. Anal. Chem. 2018, 90, 13723-13728.

(5) Sun, Y.; Wang, Q .; M i, L.; Shi, L.; Li, T . Anal. Chem. 2019, 91, 12948-12953. 